\title{
Preservação da liberdade no anteprojeto de Código de Processo Penal.
}

\author{
Basileu Garcia \\ Catedrático de Direito Penal na Faculdade de \\ Direito da Universidade de são Paulo.
}

1. O anteprojeto de autoria do Prof. HÉlio Tornaghi constitui uma cuidadosa revisão do Código vigente, que lhe serviu de estrutura. Houve, porẻm, transformações profundas, de modo geral boas, e muitas excelentes. Acha-se redigido com propriedade. A matéria está sistematizada com apuro e até com certo requinte professoral, como se observa na abundância dos conceitos, que chegam a ultrapassar o necessário. Tal abundância, porém, non nocet, e prefiro não apontar o que me parece demasiado, porque, no conjunto, a orientação satisfaz, e seria impertinência referir nugas que a revisão do próprio autor será a primeira a encontrar.

Alega-se que a ação penal, nesse anteprojeto, continuará vagarosa no Brasil. Entretanto, não se devem esperar das leis processuais soluções miraculosas quanto à celeridade, interêsse que não se sobrepõe ao da segurança. Possivelmente, haverá ritos mais eficientes que os do anteprojeto, mas êle representa um grande progresso. Cumpre não esquecer que uma tarefa paralela compete às leis de organização judiciária, que devem ser aperfeiçoadas de maneira a dotar a Justiça criminal no Brasil de um aparelhamento eficaz na luta contra o crime. 
A apreciação que vou fazer é restrita. Cinge-se ao setor alusivo à coerção processual sôbre pessoas e apanhará apenas o que se me afigurou mais digno de nota numa palestra em tempo limitado.

2. Partindo do art. 441, observo inicialmente a falta de um conceito de prisão provisória. Não porque sejam indispensáveis os conceitos na lei, mas porque, omitindo-o, o anteprojeto excetua no seu plano, pródigo como é em conceituações e definições.

Prisão provisória é expressão que designa tôdas as formas de prisão preventiva lato sensu, inclusive, portanto, a prisão decorrente de pronúncia ou de condenação sem trânsito em julgado.

A rubrica "prisão provisória", colocada na secção $I$, Capítulo III do Título VII, abrange, porém, três temas: $1 .^{\circ}$, dísposições gerais; $2 .^{\circ}$, prisão em flagrante; $3 .^{\circ}$, prisão preventiva, ficando assim excluída a prisão em virtude de pronúncia ou de sentença condenatória recorrível.

Quanto à decorrente de pronúncia, lê-se, bem mais adiante, no art. 596, que "a sentença de pronúncia acarreta a prisão provisória do acusado". Quanto à prisão decorrente de sentença condenatória recorrivel, consta no art. 360: "É efeito da sentença condenatória recorrivel ser o réu prêso ou conservado na prisão, assim nas infrações inafiançáveis, como nas afiançáveis enquanto não prestar fiança".

Para se aplicarem ou não os dispositivos sôbre prisão provisória, considera como tal o anteprojeto a prisão resultante de pronúncia e de condenação? 0 art. 596 leva a responder afirmativamente no que toca à primeira dessas duas modalidades. Resta, quanto à segunda, dúvida, que é relevante, porque o art. 460 estabelece: “A prisão provisória nâo poderá ultrapassar, em caso algum, o prazo de oito meses nos casos de procedimento ordinário ou especial, de cinco meses nas hipóteses de procedimento sumário e de dez dias nas de procedimento sumaríssimo". 
Quero crer que êsse dispositivo foi escrito pensando-se apenas na prisão em flagrante e na prisão preventiva stricto sensu. Mas atinge inevitàvelmente a prisão em virtude de pronúncia, que é qualificada também como prisão provisória. Deve então ser sôlto o homicida que permanece oito meses aguardando o julgamento ou a renovação dêste em conseqüência de protesto por nôvo juri ou apelação? Não há conveniência em preceituá-lo.

Seria preferivel que o art. 460 excluísse expressamente a prisão resultante de pronúncia e a de condenação recorrível, às quais - para completar o sistema - conviria fazer alguma referência nessa secção relativa à prisão provisória, ainda que com rápidas remissões à disciplina traçada em outros lugares do anteprojeto.

3. Tendo firmado, nos têrmos da norma constitucional, a obrigatoriedade da comunicação do fato da prisão ao juiz competente (art. 442), o anteprojeto insere normas que dinamizam a ação da Justiça nesse assunto. $O$ juiz perde a possibilidade de ser, como acontece atualmente, um espectador inerte de violências. É obrigado a conhecer realmente da comunicação, para revogar a prisão ilegal (art. 443), não podendo eximir-se do pronunciamento que lhe cabe, a pretexto de não contar com esclarecimentos. 0 parágrafo único do art. 443 declara que "deverá êle, desde logo, tomar providências para informar-se e julgar".

Assim, se a prisão, a despeito de ilegal, fôr mantida, torna-se o magistrado a autoridade coatora, e contra êle é que será impetrado habeas-corpus.

Desaparece, no anteprojeto, aquela debatida dúvida quanto a saber se o despacho de relaxamento da prisão constitui necessàriamente concessão de habeas-corpus, para comportar ou não recurso ex-officio. O anteprojeto não cogita, para caso algum, de tal recurso.

$\mathrm{O}$ art. 444 manda que o juiz promova "a responsabilidade da autoridade coatora se lhe parecer configurado o crime previsto no art. 379 do Código Penal (exercício arbi- 
trário ou abuso de poder) ou qualquer outro". O art. 379 é do anteprojeto HungRIa e repete a maior parte das hipóteses do art. 350 do Código vigente. Sugiro - e a sugestão visa aumentar a utilidade do preceito processual do art. 444 que se acrescente um inciso aos vários do parágrafo único daquele art. 379 , de maneira a considerar-se também como crime de exercício arbitrário ou abuso de poder a omissão de quem, infringindo o art. 141, § 22, da Constituição, deixe de fazer ao juiz a comunicação, a que está obrigado, da prisão efetuada.

4. O anteprojeto não admite a chamada prisão para averiguações policiais, a qual, não tendo sido contemplada, como efetivamente não o poderia ser, incide nas medidas punitivas e de proteção à liberdade inscritas nos arts. 443 e 444. Quero acentuar que a vedação aqui é mais cautelosa, como resulta do disposto no art. 13 acêrca da incomunicabîlidade do indiciado, no inquérito. No Código vigente, o art. 20, em certa época, deu lugar ao argumento - aliás, improcedente, - de que a detenção para averiguações policiais era possível, por três dias, prazo durante o qual aquêle texto permite manter o indiciado incomunicável. $\mathrm{O}$ art. 13 do anteprojeto reza: "A autoridade que preside ao inquérito poderá manter incomunicável o indiciado que estiver legalmente prêso, por três dias no máximo".

5. A inviolabilidade do domicílio não se acha convenientemente resguardada, sem embargo da alusão respeitosa que lhe faz o art. $449^{1}$. Que acontece, perante o anteprojeto, se o capturando se homizia, à noite, em uma residência particular, sua ou de outrem? Responde o anteprojeto que o executor da captura deve pedir a entrega e, não sendo atendido, "fará guardar tôdas as saídas, tornando a

1. Art. 449. A prisão poderá ser efetuada em qualquer dia e a qualquer hora, respeitadas as restrições relativas à inviolabilidade do domicílio. 
casa incomunicável e, logo que amanheça, arrombá-la-á e efetuará a prisão", ajuntando o parágrafo único que "o morador que se recusar à entrega do capturando será levado à presença da autoridade para que contra êle proceda como de direito, se sua ação configurar qualquer infração penal".

Foi aí repetido o que consta do vigente estatuto processual, à sua vez inspirado em antigas disposições. Mas é tempo de rever a matéria à luz da ampla garantia constitucional da inviolabilidade do domicílio.

A casa, à noite, não deve ser mantida incomunicável, pelo fato da recusa do morador a entregar quem nela se encontra. $O$ direito ao domicílio não se cinge a estar nele, senão também a sair e entrar como queira e quantas vêzes queira, o que a incomunicabilidade impede a pessoas que nada têm a ver com o crime. Tornar a casa incomunicável equivale em certos casos a obrigar o morador a permitir a prisão: por exemplo, se o fugitivo a que dá abrigo se acha ferido e precisa com urgência da visita de um médico.

E a necessidade de condução, à presença da autoridade, do morador que legìtimamente se oponha à intrusão noturna em seu lar presta-se a ameaças, no instante em que a entrega do fugitivo é pedida, o que implica em constrangimento violador da garantia constitucional. Deve ser banida a providência de condução do recusante, substituindo-se por informes do executor à autoridade, para que providencie o que fôr de direito.

$\mathrm{E}$ por que estipular que o executor, logo que amanheça, arrombará a casa, para efetuar a captura? O natural seria que, antes, pedisse amistosamente a entrega do capturando, já que a recusa, por ser noite, era legítima.

6. O anteprojeto declara que "é permitido o emprêgo de algemas e outros utensílios destinados à segurança, desde que não atentem contra a dignidade ou a incolumidade física do prêso" (art. $453, \S 10^{\circ}$ ). A rubrica marginal dêsse texto é "Algemas, etc.". Eu votaria pela redução do enunciado à sua parte inicial, permitindo tão-só o emprêgo de 
algemas e, assim, suprimindo aquêle imponderável "etc.", que aumenta desnecessàriamente os métodos de contenção do prêso.

o uso de algemas é, por vêzes, imprescindível. Já assim opinei há alguns anos, quando o problema surgiu em São Paulo, perante a falta de regra expressa no estatuto processual vigente. Não me pareceu que a lacuna fôsse impediente do uso moderado, imposto por uma necessidade inelutável. $\mathrm{O}$ preceito do anteprojeto é útil à clareza. Mas a referência a "outros utensílios" pode ser suprimida.

Dir-se-á que em certos casos não se acham algemas à disposição do autor da captura, e êle terá que recorrer a outros meios. Quando tal aconteça, respondo, ninguém o censurará por isso. A legitimação decorrerá das circunstâncias, como legítimo vinha sendo reputado o uso de algemas, sem texto expresso permissivo. O perigo do "etc." e da evasiva "outros utensílios" está em que pode levar a abusos, não evitados pela restrição "desde que não atentem contra a incolumidade física do prêso", pois envolve apreciação muito subjetiva.

Ao invés, creio que melhoraria o dispositivo uma advertência no sentido da excepcionalidade do recurso às algemas, para que os nossos investigadores e oficiais de justiça não pensem que devem proceder em todos os casos como nas detenções que se vêem nos filmes norte-americanos.

7. Parece-me inconveniente e mesmo perigoso o disposto no $\S 3 .^{\circ}$ do art. 453: "Na hipótese de tentativa de fuga o emprêgo de armas só será permitido quando não causar mal grave e fôr necessário". Não faz falta. A tentativa de fuga é forma de resistência passiva, ou desobediência, e o art. 453 já disse que "não serà permitido o emprêgo da fôrça, salvo a indispensável no caso de desobediência, resistência ou tentativa de fuga". Em qualquer das três hipóteses compreendidas na ressalva se abrange o uso moderado de fôrça (portanto, de arma) para impedir a fuga. 
Nunca se negou que o emprêgo de arma está compreendido no de fôrça, utilizado êste vocábulo sem qualquer qualificação restritiva.

É longo o atual art. $453^{2}$, porque reune, como convinha, dois preceitos do Código vigente. E diz tudo o que é preciso. O uso dos meios necessários para vencer a resistência do capturando ou de terceiros é intuitivamente legítimo, desde que proporcionado. Em conseqüência, soa como uma superabundância o seu $\S 2 .^{\circ}$, embora pareça escrito para restringir: "O recurso ao uso de armas só se justifica quando absolutamente necessário para vencer a resistência". Em verdade, será entendido na prática como uma ampliação do que consta do Código vigente, e incrementará o uso d̃e armas, que deixará de ser um último recurso, para constituir um recurso vulgar, sob o pretexto de que é "absolutamente necessário para vencer a resistência".

E o $\S 3 .^{\circ}$ é ambíguo:

a) Como pode, quem emprega armas, saber de antemão que não causará mal grave?

b) Em que consiste a necessidade, que o dispositivo tem como eficaz à legitimação do uso de armas? A necessidade de impedir a fuga? Então o uso de armas será normal, tôdas as vêzes em que haja tentativa de fuga.

c) Como as duas condições "quando não causar mal grave" e "fôr necessário" são, ante o desejo de usar armas, considerações aleatórias, sujeitas a apreciação repentina, a Justiça acabará dispensando-as nos casos concretos, sob o fundamento de que o autor da captura incorreu em êrro de fato. E permanecerá a licença ilimitada ao uso de armas contra o que tenta fugir.

2. Art. 453. Não será permitido o emprêgo de fôrça, salvo a indispensável no caso de desobediência, resistência ou tentativa de fuga. Se houver resistência por parte de terceiros, o executor e as pessoas que o auxiliarem poderão também usar dos meios necessários para vencê-la e para defender-se. De tudo se lavrará auto subscrito pelo executor e por duas testemunhas. 
8. Quanto à prisão em flagrante, o anteprojeto enfrentou uma questão sôbre a qual é omisso o Código. Absteve-se êste de regular-lhe o cabimento nos crimes cujo processo depende da iniciativa do ofendido. A solução que, comentando as disposições vigentes, me pareceu curial, é admitir a captura em flagrante, condicionando, porém, a efetividade da prisão ao pronunciamento do ofendido, perscrutado com urgência pela autoridade.

$O$ anteprojeto, sem aludir aos crimes de ação pública mediante representação, - e é uma falha - subordina o próprio ato da captura à iniciativa do ofendido (parágrafo único do art. $462^{3}$ ), o que é inconveniente e mesmo quase de todo impraticável. As pessoas que em geral efetuam prisão em flagrante - particulares e policiais, leigos em direito - não têm como entrar em distinções quanto à natureza da ação cabível, e em graves crimes de ação privada o ofendido ou seu representante legal pode não estar em condições de manifestar-se no próprio instante da ação delituosa. Suponha-se um hediondo atentado sexual contra criança, cujo pai se acha ausente.

Entendo que seria melhor admitir a captura, reclamando, porém, para se lavrar o auto de flagrante, manifestação da vítima ou quem a represente, em breve lapso de tempo, a ser fixado e que poderia ser de algumas horas. A regra poderia ser estendida aos crimes de ação pública mediante representação.

Estabelece o art. 464, na sua parte final, que, se se tratar de crime de ação privada, o prêso será pôsto em liberdade logo após a lavratura do auto. Qual a razão? Se a prisão foi precedida de pedido da vítima, é provável que esta queira oferecer a queixa. Talvez o anteprojeto

3. Art. 462. Qualquer um pode e as autoridades e seus agentes devem prender quem estiver em qualquer das situações do artigo anterior ou seu parágrafo.

Parágrafo único. Nos crimes de ação privada, a prisão em flagrante dependerá de solicitação do ofendido quando não fôr por êle próprio efetuada. 
haja decidido pela forma exposta por se afigurar que essa expectativa de uma ação penal, que não é obrigatória, não justifica a prisão. Por mim, preferiria que a conservação prêso do paciente se prolongasse pelo prazo fixado para o of erecimento da queixa, prazo muito breve, em se tratando de indiciado prêso, e que é de cinco dias no anteprojeto.

9. A lavratura do auto de flagrante não implica indeclinàvelmente em manter-se prêso o indiciado, em relação a quem podem não militar efetivos indícios. Será então libertado, como determina o Código e o repete o anteprojeto. Inova, porém, êste uma interessante medida. O juiz que discorde da autoridade, assim como deve relaxar a prisão ilegal, "ordenará a prisão do ilegalmente sôlto" (art. 466, n. $\left.{ }^{0} \mathrm{I}\right)$. Essa forma de correção judicial não se faz sob decreto de prisão preventiva, mas como simples restauração de um flagrante que foi imerecidamente invalidado.

10. O Código permite ao juiz conceder ao prêso em flagrante a liberdade provisória quando verifique ocorrer uma justificativa: legítima defesa, estado de necessidade, cumprimento de dever legal, exercício regular de direito. O anteprojeto alarga no art. $474^{4}$ a concessão a outras hipóteses, e faz bem.

Entretanto, seriam úteis duas sortes de retoques no texto:

a) Substituir-se a frase "quando o juiz verificar" por outra que o vincule menos a êsse pronunciamento liminar. Dir-se-ia: "quando do auto de prisão em flagrante resultarem indícios de que" ou, se se quiser: "resultarem suficientes indicios de que..".

4. Art. 474. Quando o juiz verificar pelo auto de prisão em flagrante que o agente praticou o fato, nas condições dos arts. 17, 18, 19, 21, 22, 23, 24, 25 e 54 do Código Penal, poderá, depois de ouvir o Ministério Público, conceder ao réu liberdade provisória, mediante têrmo de comparecimento a todos os atos do processo, sob pena de revogação. 
Semelhantemente, poderia ser modificado o art. 480 , sôbre a prisão preventiva, em cuja não decretação não deve haver motivo para o juiz manifestar prejulgamento.

Mas o melhor é suprimir êsse texto do art. 480, inspirado na legislação vigente, na qual é necessário como exceção à obrigatoriedade da prisão preventiva nos crimes punidos com mais de dez anos de reclusão. Abolida a prisão preventiva obrigatória, já não será mister advertir o magistrado de que não deve decretar a prisão se é provável a absolvição justa.

b) Harmonizar-se o referido art. 474 com o art. $480^{5}$ (caso êste seja mantido), para que ambos cogitem das mesmas exceções à prisão. 0 paralelismo, na redação do anteprojeto, não é perfeito e, por sinal, a inclusão do art. 54 do anteprojeto Hungria, impedindo a prisão em flagrante quando ocorram as circunstâncias atenuantes arroladas nesse dispositivo, parece-me excessiva. Deveria a menção limitar-se à atenuante consistente em ser o agente menor de 21 anos ou maior de 70.

11. A grande inovação do anteprojeto, nesse capítulo, está em abolir a prisão preventiva obrigatória. Acredito que o ilustre autor do trabalho em exame reflete, nessa diretriz, a aspiração dominante. Em verdade, o art. 312 do Código vigente, embora dutilizado pela exigência de certeza da materialidade da infração, tem-se prestado a muito exagêro de juízes, nem sempre consertado pelo habeas-corpus a tempo de poupar a liberdade individual a pesado gravame. São conhecidos casos de acusação de peculato, formulada em meio a agitações emocionais, acarretando a prisão preventiva de quem não se sabe se praticou crime.

5. Art. 480. A prisão preventiva em nenhum caso será decretada se o juiz verificar pelas provas constantes dos autos ter o agente praticado o fato nas condições dos arts. 17, 18, 21, 22, 23 e 25 do Código Penal. 
A minha posição em face dêsse problema, porém, não é a mais radical. Em nosso país, é muito frouxa a repressão ao homicídio, porque está entregue ao júri. Seria bom que ao escândalo freqüente da impunidade não se adicionasse a franquia da liberdade do homicida no decurso da ação penal, o que é verdadeiramente chocante, para a sensibilidade pública. Podia-se manter, para os crimes dolosos contra a vida punidos com reclusão superior a dez anos, a prisão preventiva obrigatória, com o temperamento - mais que suficiente - da concessão da liberdade provisória em havendo indícios de escusa relevante, nos têrmos já comentados.

12. Reza o art. 476 que a prisão preventiva poderá ser decretada em qualquer fase do inquérito policial ou do processo judicial, "enquanto não transitar em julgado a sentença definitiva". Portanto, pode ser decretada após sentença condenatória recorrível. Esta, no entanto, produz o efeito da prisão do réu, nos crimes inafiançáveis, o que torna inviável um decreto de prisão preventiva, assim como nos crimes afiançáveis, se não fôr prestada a fiança. Uma vez prestada, já năo cabe a prisão preventiva. Poderá haver a cassação da fiança (art. 502) se se reconhecer o seu não cabimento. E nessa hipótese ocorrerá a prisão, sem decreto de prisão preventiva.

Não compreendo, pois, o motivo daquele apêndice que coloquei em relêvo no art. 476 .

13. Quanto à fiança, o anteprojeto af asta corretamente a dúvida existente acêrca do limite penal, que é proporcionado pela pena cominada, prevalecendo, todavia, a pena concretizada na sentença condenatória recorrivel (arts. 486, n. ${ }^{\circ}$ I, e 491).

Deixou, porém, de eliminar um dos defeitos da legislação vigente, na qual não se explica se a idade, a levar em aprêço, do réu menor de 21 anos ou maior de 70, que tem 
direito à fiança, é a que conta na época do crime ou na da fiança. Por eqüidade, convém que a permissão para afiançar-se ocorra nas duas hipóteses, que são antinômicas, pois se a época do fato pode ser favorável ao delinqüente juvenil, pode ser desfavorável ao delinqüente senil, que só no decurso do processo alcance os 70 anos, e se a época da fiança pode ser favorável ao delinqüente senil, que completou durante o processo os 70 anos, pode ser desfavorável ao delinqüente juvenil, que ultrapassou o limite de 21 anos.

Constitui uma interessante inovação em matéria de fiança o disposto no art. 511, que concede ao afiançado, devidamente intimado, prazo de trinta dias para apresentar-se à prisão, sob pena de perder a fiança, após o trânsito emi julgado da sentença condenatória.

14. O anteprojeto traz disposições sôbre a aplicação provisória de interdições de direitos e de medidas de segurança, equivalentes às que existem no estatuto processual vigente. Este as desenvolveu em harmonia com preceitos do Código Penal de 1940, que previu a aplicação provisória de tais providências. Mas o anteprojeto Hungria não segue a mesma trilha. Nada diz sôbre o cabimento provisório de umas e outras. Como o anteprojeto de Código de Processo Penal se declara consentâneo com o anteprojeto Hungria, poderia advir dúvida quanto à legitimidade das disposições processuais, que porventura seriam tidas como desautorizadas pelas normas penais acêrca das interdições de direitos e medidas de segurança.

Aventa-se a dúvida para afastá-la. Em verdade, a aplícação provisória das aludidas providências é assunto nìtidamente de processo, independente de previsão no direito substantivo, tal como acontece com a prisão preventiva perante a pena privativa de liberdade.

15. Aduzirei agora algumas observações acêrca da disciplina do habeas-corpus. 
Parece-me algo artificial a distinção, contida nos arts. 526 e 527, entre ilegalidade e abuso de poder. Em todo abuso de poder há ilegalidade e a ilegalidade via de regra se caracteriza por um abuso de poder.

$O$ anteprojeto deixa incerteza quanto a caber ou não o habeas-corpus para o trancamento de ação penal desapoiada, manifestamente, em quaisquer indícios, e conviria que tomasse partido acêrca dêsse ponto, que a tanta divergência tem dado ensejo nos tribunais. A jurisprudência registra casos, embora não muito numerosos, de concessão, feita sem embargo de estar a peça vestibular do processo redigida com esmero, adrede a neutralizar a argüição de inexístência de crime em tese.

Mais protegida ficará a liberdade individual com a permissão do habeas-corpus para coibir processos aberrantes na sua iniqüidade. A questão é delicada, porque também há conveniência de evitar que o heróico remédio se converta em panacéia a ser experimentada em todos os casos.

Lê-se no art. 23 que a denúncia "terá de ser apresentada sempre que houver: a) prova de fato que, em tese, constitua crime; b) prova que abone a suspeita de autoria". A contrario sensu, a denúncia não poderá ser apresentada se faltarem êsses elementos. $O$ constrangimento resultante do seu oferecimento e aceitação será, pois, ilegal. O habeas-corpus não deve ser recusado. Mas na longa lista de hipóteses dos arts. $526^{6}$ e $527^{7}$ não figura a da total falta de base para o processo.

6. Art. 526. Haverá ilegalidade:

I - quando o cerceamento da liberdade fôr ordenado por quem não tem competência para tal;

II - quando ordenado ou efetuado sem as formalidades legais.

7. Art. 527. Haverá abuso de poder:

I - quando a liberdade de ir e vir fôr cerceada fora dos casos previstos em lei;

II - quando alguém estiver prêso por mais tempo do que determina a lei;

III - quando cessado o motivo que autorizava o cerceamento; 
O dispositivo que mais se adapta à situação em aprêço é o do n. ${ }^{\circ}$ I do art. 527, que refere existir abuso de poder "quando a liberdade de ir e vir fôr cerceada fora dos casos previstos em lei". Com ligeira correção, êle se flexibilizará mais. Proponho que se diga: "quando a liberdade fôr cer. ceada fora dos casos previstos em lei".

Terá o autor do anteprojeto, com aquêle tradicional "ir e vir", pensado no perigo de ampliar demais o habeas-corpus? Não é de temê-lo. Confiemos na sua estratificação atual, que lhe traça balizas razoàvelmente firmes.

O enunciado, que proponho, por ser mais amplo, figuraria melhor no fim do elenco, como um arremate, cabendo em face dêle dispensar-se o que se mostra casuístico demais, como por exemplo o texto do inciso VI, que diz haver abuso de poder "quando alguém fôr prêso preventivamente por fato típico, porém excepcionalmente lícito (art. 25 do Código Penal; Cód. Proc. Penal, art. 480)". Para que dizê-lo? Pois a hipótese não é de cerceamento da liberdade (mesmo conservado o "ir e vir") fora dos casos previstos em lei?

De resto, a incluir-se êsse inciso VI, então se teria de dilatá-lo para prever de expresso a ameaça de prisão, proveniente de indevido decreto de prisão preventiva ainda não cumprido. Falando em "quando alguém fôr prêso", o dispositivo parece esquecer essa eventualidade, que por sinal é mais comum.

Sob outro aspecto não considero boa a redação do inciso VI. Aludindo a "fato típico excepcionalmente lícito", tem em mira as descriminantes ou causas justificativas,

IV — quando alguém não fôr admitido a prestar fiança que a lei concede;

$\mathrm{V}$ - quando alguém estiver sendo processado ou tiver sido condenado por fato que não constitua crime em tese (fato atípico);

VI - quando alguém fôr prêso preventivamente por fato típico porém excepcionalmente lícito (art. 25 do Código Penal; Cód. Proc. Penal, art. 480);

VII - quando estiver extinta a punibilidade;

VIII - quando o processo fôr manifestamente nulo. 
mas, como já se viu, o projeto estende o não cabimento da prisão preventiva a outras situações jurídicas, como o confirma o mesmo inciso VI ao remeter o leitor ao art. 480 . Ainda quanto ao habeas-corpus, uma útil inovação aparece no parágrafo único do art. 529: "O pedido será rejeitado se o paciente a êle se opuser". Recentemente, o Supremo Tribunal Federal censurou, com pesadas e justas increpações, determinado impetrante espontâneo de um habeascorpus que o requerera maliciosamente, com o indissimulado propósito de difamar o paciente.

16. O anteprojeto inadvertidamente reitera uma regra má do atual Código. O parágrafo único do art. 538, idêntico ao parágrafo único do art. 664 do estatuto vigente, preceitua: "A decisão será tomada por maioria de votos; havendo empate, se o Presidente não tiver tomado parte na votação, proferirá voto de desempate; no caso contrário prevalecerá a decisão mais favorável ao paciente".

Assim como em outros tribunais do país, pelo Regimento Interno do Tribunal de Justiça de São Paulo o Presidente da Secção Criminal é o Corregedor Geral da Justiça, cujo comparecimento aos julgamentos de habens-corpus não é constante, porque outras atribuições o solicitam. Freqüentemente encontra-se fora da Capital, em viagem de correição. Substitui-o na presidência o mais antigo membro das Câmaras Criminais. No Tribunal de Alçada, a Presidência da Secção Criminal compete ao Presidente do Tribunal, que raro dispõe de tempo para êsse encargo, no qual é também substituído pelo mais antigo componente da Secção Criminal.

O preceito em aprêço cria para o Presidente efetivo da Secção Criminal uma difícil conjuntura. O seu comparecimento, que é eventual, só pode concorrer para a denegação do habeas-corpus. Apenas lhe é dado votar para converter a concessão da ordem em indeferimento ou manter uma concessão que estava consumada sem o seu voto. Não votando, a ordem acha-se concedida. 
Se a presença do Presidente ocorresse diuturnamente, paciência. Mas o seu surgimento esporádico suscita-lhe problemas, porque o seu comparecimento nunca pode ser benéfico aos que recorrem à impetração.

Há quem entenda que, ausente o Presidente efetivo, deve ser convocado para desempatar, se com o voto do Presidente substituto se estabeleceu o empate. Essa opinião é absurda. Tal convocação não está prevista no texto do Código, repetido no anteprojeto. E a solução seria difìcilmente exequível, pelas delongas e complicações a que obrigaria, com a repetição do julgamento, inclusive defesa oral, ainda mais porque, quando o Presidente é o Corregedor, se terá de esperar o seu retôrno, se se encontrar em viagem.

O preceito sugere ao Presidente, como solução mais equânime, o desempate infalivelmente a favor, o que não é uma solução juridicamente exata.

O texto do anteprojeto deveria dispor, simplesmente: "A decisão será tomada por maioria de votos. Havendo empate, prevalecerá a decisão mais favorável ao paciente". 